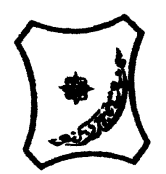

Bayero Journal of Pure and Applied Sciences, 8(1): $50-55$

Received: November, 2014

Accepted: June, 2015

ISSN $2006-6996$

\title{
PHOTOSYNTHETIC GAS EXCHANGE AND CHLOROPHYLL IN BAMBARA GROUNDNUT (VIGNA SUBTERRANEA L. VERDC.) SUBJECTED TO WATER DEFICIT
}

\author{
Muhammad, Y. Y. ${ }^{a^{*}}$ and Massawe, $F .^{b}$ \\ ${ }^{a}$ Department of Biochemistry, Bayero University, PMB 3011, Kano, Nigeria. \\ ${ }^{b}$ School of Biosciences, University of Nottingham, Malaysia Campus, 43500 Semenyih, Selangor, Malaysia \\ *Correspondence author : yymuhammad.bch@buk.edu.ng
}

\begin{abstract}
The study evaluated the response of two Bambara groundnut (Vigna subterranea L. Verdc.) landraces sourced from contrasting environments to periods of water deficit initiated at vegetative stage. The two landraces AHM-753 and Bogor, from Namibia and Indonesia, respectively, were grown in pots and irrigation was withheld 30 days after sowing in stressed group while the control plants were fully watered. The responses were studied by measurements of relative water content (RWC), photosynthetic gas exchange, and SPAD chlorophyll. RWCand gas exchange parameters were found to decrease in stressed plants. Significant $(P<0.001)$ decrease in SPAD chlorophyll concentration was seen only in Bogor landrace. The results showed a possible drought avoidance strategy in Bambara groundnut in response to water deficit. The results pointed a greater tolerance to the imposed drought in the landrace AHM-753 compared to Bogor suggesting that the origin of the landrace and the environment it is adapted to determine its response to water deficit. Keywords:Bambara groundnut; Chlorophyll; Gas exchange; Photosynthesis, Water deficit
\end{abstract}

\section{INTRODUCTION \\ Bambara groundnut (Vigna subterranea (L.)} Verdc.) is an important legume crop commonly grown for its seeds by subsistence farmers in many parts of Africa (Linnemann and Azam-Ali, 1993; Basuetal., 2007). It has great economic potentials and towards food security considering its superb nutritional composition and other properties. Bambara groundnut has been referred to as a drought tolerant plant (Berchieet al., 2012; Collinson et al., 1999) and was reported to produce relatively greater seed yield than other legumes under the same conditions (Jogensenet al., 2010). Mwaleet al. (2007) observed a reduction in yield among Bambara groundnut landraces after drought imposition, even though the results pointed at the resilience potential of the species to drought. Jorgensen et al. (2010) observed differences in the response of two Bambara groundnut landraces and attributed that to the climatic conditions in the area of collection.

Plant growth and productivity are unfavourably affected by nature by means of various biotic and abiotic stress factors. Drought is the main abiotic stress factor limiting crop production, leading to decreases in crop yields after exposure to constant or intermittent periods of drought (Chaveset al., 2003).Water is vital for plant growth and makes up 75 to 95 percent of plant tissues. Plants use water and $\mathrm{CO}_{2}$ to form sugars and more complex carbohydrates. Water also acts as a carrier of nutrients and a cooling agent and as an intercellular reaction medium and provides an element of support through turgor (Rehmanet al., 2005).Water limitation is already one of the major threats in crop production and it is expected to get significantly worse in coming decades (Cominelliet al., 2009). Plants act in response and acclimatize to drought stress at the cellular, molecular, physiological and biochemical levels (Uranoet al., 2010).Limited evidence exists on the degree and mechanism of resistance of Bambara groundnut to drought.In order to improve the yield and to fully exploit the great potentials of Bambara groundnut, a more thorough understanding of the mechanisms of its response to drought need to be achieved. The aim of this

\section{MATERIALS AND METHODS}

Two landraces of Bambara groundnut Bogor (from Indonesia) and AHM-753 (Africa) were used. The plants were grown under natural environmental conditions in a shade house, the environmental data were monitored and logged every 30 minutes throughout the study period by a mini weather station (Watchdog 2000 Series, Spectrum Technologies, Plainfield, IL, USA). Photosynthetically active radiation (PAR) ranged between $100-790 \mu \mathrm{mol}$ $\mathrm{m}^{-2} \mathrm{~s}^{-1}$ during the day, temperature was between 23$36 / 23-25{ }^{\circ} \mathrm{C}$ day/night, while humidity ranged from $52-99 \%$. The plants were grouped into three with four replicates per group. The first group(ControlGroup)was irrigated to field capacity once every two days. The second and third groups were subjected to water deficit at 30 days after planting by totally withholding irrigation fora period of two weeks (stressed group T2) and four weeks (stressed group T3). At the end of the respective stress periods, irrigation was resumed for two weeks to assess recovery. Leaf water status was estimated by measuring the relative water content (RWC) according to the method described by Barrs and Weatherly (1986). 
Gas exchange measurements (photosynthesis, stomatal conductance and transpiration) were done weekly at $400 \mu \mathrm{mol} \mathrm{m} \mathrm{m}^{-2} \mathrm{~s}^{-1}$ PAR, reference $\mathrm{CO}_{2}$ concentration of $390 \mu \mathrm{mol} \mathrm{m} \mathrm{m}^{-2} \quad \mathrm{~s}^{-1}$ and leaf temperature of $29^{\circ} \mathrm{C}$ using Li-6400XT Photosynthesis System (Li-Cor Biosciences, Lincoln, NE, USA).Chlorophyll was measured using a SPAD 502 Plus Chlorophyll Meter (Konica Minolta, Osaka, Japan).Statistical analyses were done using Genstat software version 10.3 (VSN International Ltd).Analysis of variance (ANOVA) was carried to compare the means of values between different groups.

\section{RESULTS}

The results of relative water content (RWC) are shown in Table 1. RWC decreased significantly
$(P<0.001)$ with time after water deficit treatment in both AHM-753 and Bogor landraces. The decrease in RWC is more pronounced in Bogor compared to AHM-753. The least RWC, $56.4 \%$, was observed in Bogor after four weeks of water deficit. It is worth noting that even among the control groups; there was difference in RWC between the two landraces, being higher in Bogor. By analysis of covariance, it was seen that the effect of drought stress treatment between two and four weeks stress was significant in both cases $(P<0.001)$. The effect of genotype as well as that of the interaction between genotype and stress treatment were also significant $(P<0.05)$. The difference between the two landraces after four weeks of water stress is much pronounced, being lower

in

Bogor.

Table 1: Relative water content, RWC (\%) in well watered (Control), two weeks (T2) and four weeks (T3) drought stressed Bambara groudnut landraces before stress (BS), 2 weeks stress, 4 weeks stress and after resumption of irrigation (Recov).

\begin{tabular}{lllll}
\hline RWC (\%) & BS & \multicolumn{1}{c}{2} & \multicolumn{1}{c}{4} & Recov. \\
\hline AHM751 (Control) & $92.93 \pm 0.5$ & $91.72 \pm 1.5^{\mathrm{a}}$ & $92.19 \pm 1.8^{\mathrm{a}}$ & $91.49 \pm 2.0^{\mathrm{a}}$ \\
AHM751 (T2) & $91.94 \pm 1.5$ & $87.6 \pm 3.5^{\mathrm{b}}$ & $* 90.89 \pm 1.6^{\mathrm{a}}$ & $\square_{\text {Not sampled }}$ \\
AHM751 (T3) & $92.99 \pm 1.3$ & $\square_{\text {Not sampled }}$ & $79.00 \pm 5.5^{\mathrm{b}}$ & $90.21 \pm 1.8^{\mathrm{a}}$ \\
BOGOR (Control) & $93.30 \pm 1.7$ & $93.53 \pm 2.2^{\mathrm{a}}$ & $93.92 \pm 0.3^{\mathrm{a}}$ & $94.04 \pm 1.0^{\mathrm{a}}$ \\
BOGOR (T2) & $93.61 \pm 1.2$ & $85.32 \pm 4.3^{\mathrm{b}}$ & $* 88.78 \pm 1.6^{\mathrm{b}}$ & $\square_{\text {Not sampled }}$ \\
BOGOR (T3) & $93.34 \pm 1.3$ & ${ }^{\text {Not sampled }}$ & $56.40 \pm 5.4^{\mathrm{c}}$ & $76.49 \pm 2.5^{\mathrm{b}}$ \\
\hline
\end{tabular}

* Values after resumption of irrigation (recovery) for group T2.

$\square$ Not sampled: RWC was not determined in the group at this period in time.

Results are mean \pm standard deviation. Values within the same column bearing dissimilar superscripts are significant at $\mathrm{P}<0.001$.

The results of chlorophyll levels as estimated by SPAD chlorophyll meter readings (SCMR) are shown in Figure 1. SCMR values were generally higher in Bogor than in AHM-753 landrace. As can be deduced from the figure, there were no appreciable changes in SCMR up to two weeks of stress. But by four week of stress, the SCMR values obtained in both landraces were lower compared to the respective control plants. SCMR was significantly $(P<0.001)$ lower in Bogor after four weeks of stress and even during recovery. Decrease in SCMR values in AHM-753 were insignificant $(P>0.005)$ and improved during recovery. The SCMR values in Bogor remained low up to two weeks after stress treatment.

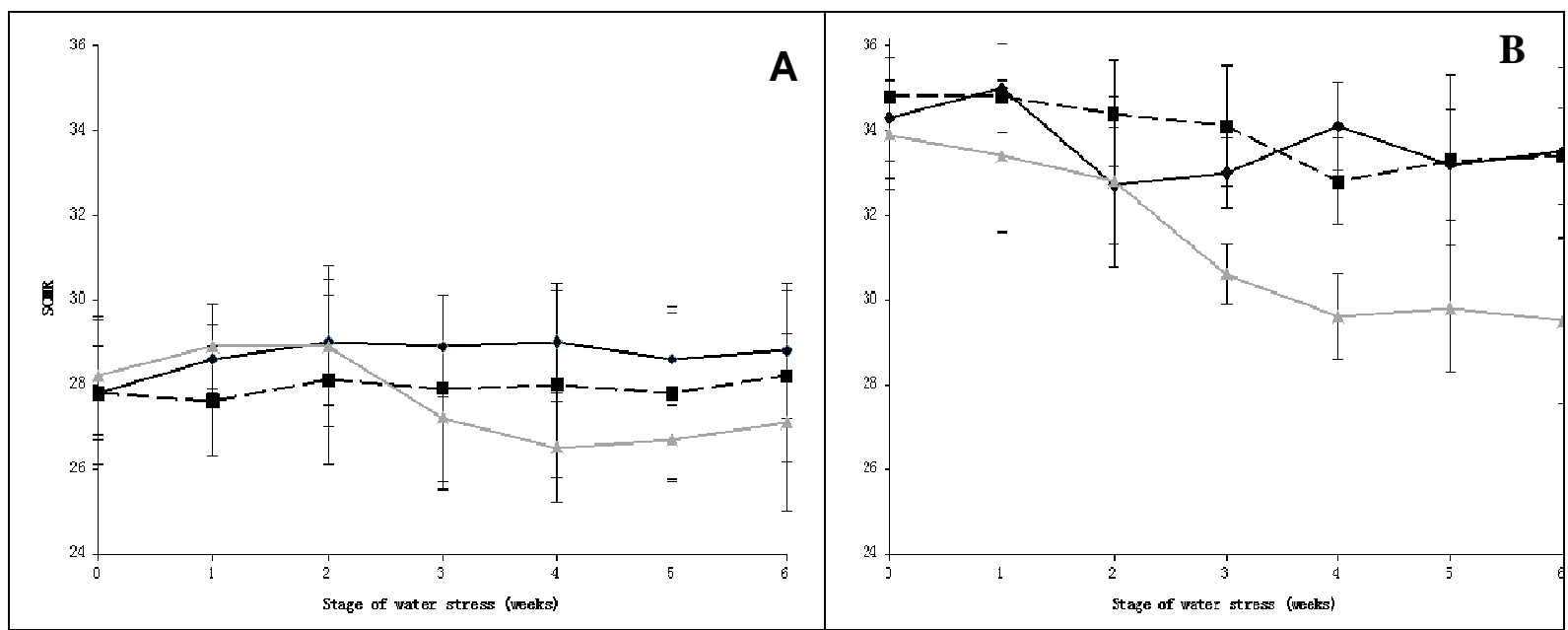

Figure 1: SPAD chlorophyll meter readings (SCMR) in two Bambara groundnut landraces after water deficit treatment and recovery (from week 3 for T2, week 4-6 for T3); (A) AHM-753 landrace and (B) Bogor landrace. Well watered ( $\square)$, T2 - two weeks stress $(\square)$, T3 - four weeks stress ( $\square$ ). Error bars represent standard deviation, $n=4$. 
Water stress caused in both landraces progressive decreased transpiration, stomatal conductance and photosynthesis (Figure 2). Transpiration $(E)$ was generally higher in Bogor than in AHM-753 landrace. In both landraces, the effects were more pronounced after four weeks of stress. $E$ was significantly $(\mathrm{P}<0.001)$ higher in control plants compared to stressed after two weeks of stress. Plants exposed to only two weeks of stress fully recovered in $E$ one week after irrigation was resumed in both landraces. In contrast, $E$ was still low in plants stressed for four weeks even during recovery.
Similarly, stomatal conductance $\left(g_{s}\right)$ decrease was more pronounced in Bogor and it was significantly lower in stressed plants by three weeks of stress. Moreover, there was a decrease with time in $g_{s}$ even among the control seedlings. Photosynthetic assimilation rate $\left(P_{n}\right)$ has a relatively similar pattern of decrease in both landraces and was significantly lower $(\mathrm{P}<0.05)$ in stressed compared to well watered control plants. $P_{n}$ increased insignificantly during recovery in plants stressed for four weeks in both landraces.

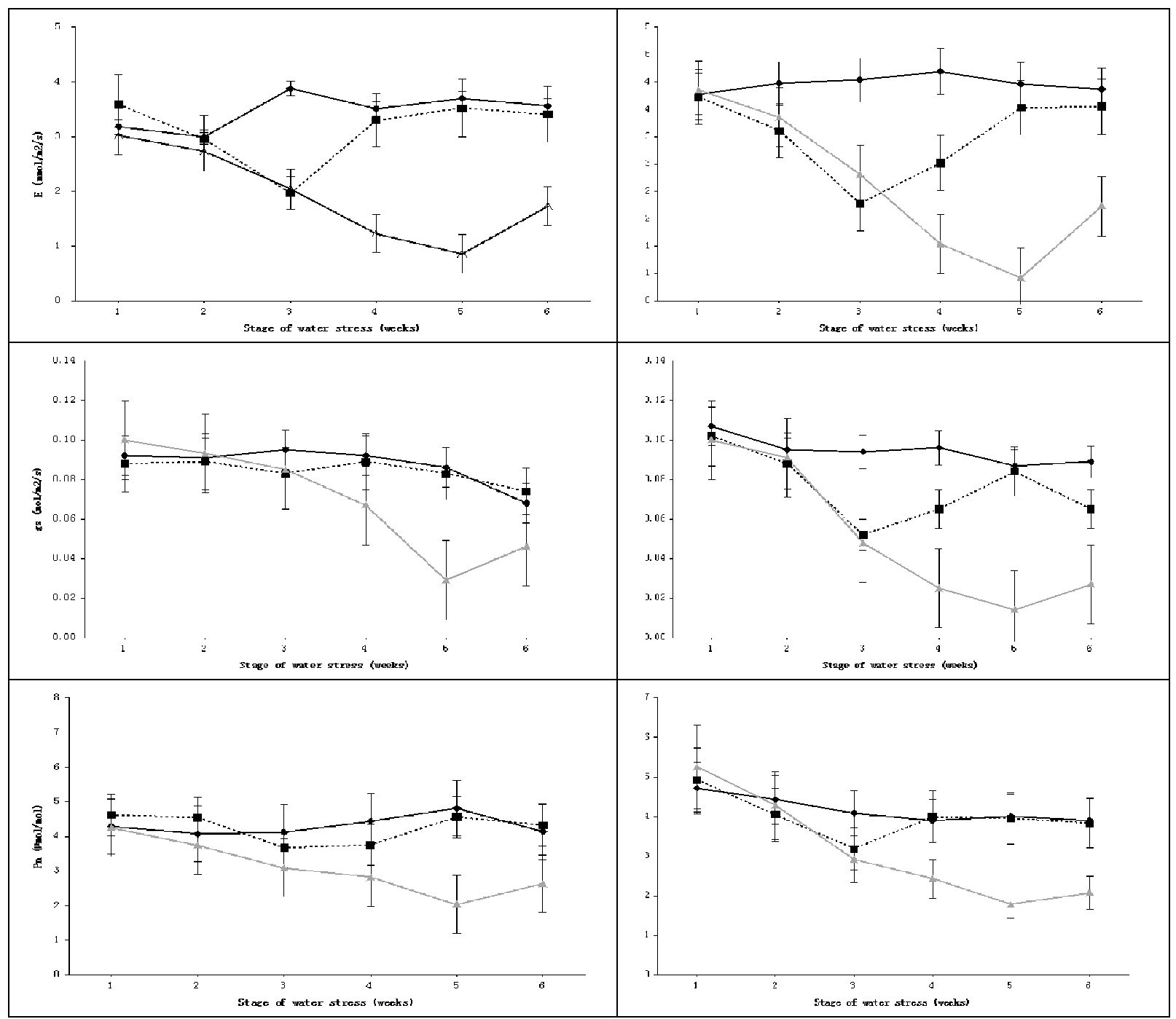

Figure 2: Changes in transpiration $(E)$,stomatal conductance $\left(g_{s}\right)$ and photosynthetic $\mathrm{CO}_{2}$ assimilation rates $\left(P_{n}\right)$ in two Bambara groundnut landraces after water deficit treatment and recovery(from week 3 for T2, week 4-6 for T3); (A) AHM-753 landrace and (B) Bogor landrace. Well watered ( $\square$ ), T2 - two weeks stress ( $\square$ ), T3 - four weeks stress $(\square)$. Error bars represent standard deviation, $n=4$.

\section{DISCUSSION}

RWC is an indicator of plant water status and has a value in assessing plant's tolerance to drought (Kimani et al., 1994; Li et al., 2011) and its maintenance in a period of leaf water reduction is a key factor of yield stability in plants (Teulatet al., 1997). RWC can be used as a reasonable approximation of cell volume (Wilson et al., 1980) and plant metabolism is generally affected by leaf water status, which RWC is a measure of.Bogor landrace showed more decline in RWC compared to AHM-753. Similarly, comparatively higher transpiration rates and stomatal conductance $\left(g_{s}\right)$ were observed in Bogor. Differences between the two landraces in terms of transpiration rates might be correlated with the differences in leaf area between them. This might have contributed to higher water loss through the stomata leading to lower RWC (Hadley and Smith, 1990). 
Decreased RWC leads to stomatal closure (Gindabaet al., 2004) leading to decreased $\mathrm{CO}_{2}$ assimilation (Li et al., 2011). The decrease in RWC observed in this work is possibly the cause of the observed decrease in $g_{s}$ in the plants. The observed decrease in transpiration after stress might primarily be a result of stomatal closure as indicated by decreased $g_{s}$. Stomatal opening is the primary determinant of transpirational water loss (Song and Assmann, 2010). Even though there was decrease in RWC in both landraces after two weeks of water deficit treatment, the values obtained still indicated an ability of the Bambara groundnut plant to maintain relatively high leaf water status under such conditions.

Several researchers have indicated that stomata respond to ambient humidity, (Aphalo and Jervis, 1991; Sanchez-Blancoaet al., 2004) even though it is difficult to separate this response with that caused by temperature (Aphalo and Jervis, 1991) and other factors (Grantz, 1990). SanchezBlancoaet al. (2004) have also shown that the reduction in $g_{s}$ as a result of low air humidity was very variable. The plants in this work were grown in an environment with high ambient humidity levels (52-99\%). This could have affected the stomatal behaviour and might have lessened the severity of the intended water deficit imposition.

A linear relationship was shown to exist between SPAD values and extracted chlorophyll (Campbell et al., 1990; Sibley et al., 1996; Lohet al., 2000). Some studies have indicated that the linearity of the relationship may differ with plant genotype (Sibley et al., 1996) and stage and conditions of growth (Campbell et al., 1990). The accuracy of the SPAD meter values have been reported to decrease at high and low concentrations of chlorophyll (Hawkins et al., 2009). Some works have also shown that the relationship between extracted chlorophyll concentration and SCMR may be nonlinear (Hawkins et al., 2009). The observed decreased chlorophyll as suggested by SCMR might have contributed to the decline in photosynthetic capacity especially at later stages of water deficit.

The decrease observed in SCMR in both Bogor and AHM-753 landraces may be due to decreases in chlorophyll especially in newly expanded leaves as a result of general decrease in metabolic processes due to the decreased tissue water content. Similarly, water deficit usually causes an increase in the activity of chlorophyllase, an enzyme responsible for the breakdown of chlorophyll, resulting in a decrease in the amount of chlorophyll (Nunesetal., 2008). Drought has been known to affect chlorophyll content in many crops thereby reducing photosynthetic capacity (Arunyanarket al., 2008).The ability to maintain chlorophyll concentration under water deficit was suggested as part of the drought resistance mechanism in many crop plants (van der Meschtet al., 1999). Arunyanarket al. (2008) have shown that SCMR can be used as an index for selection of peanut genotypes for drought resistance.

The rate of transpiration in the Bambara groundnut landraces used in this study decreased with severity of water stress, corresponding to the decreased stomatal conductance indicating stomatal closure to preserve tissue water. Stomatal limitation was generally accepted to be the main determinant of reduced photosynthesis in drought (Chaves and Oliveira, 2004; Grassi and Magnani, 2005). This is credited to a reduction in internal $\mathrm{CO}_{2}\left(C_{i}\right)$ and assimilation which ultimately hinders photosynthesis related metabolic processes. Others reports have argued that the reduced photosynthesis is more due to metabolic impairments (Tezaraet al., 1999).

The decrease in photosynthetic assimilation rate observed corresponds with the decrease in stomatal conductance which might be due to decreased tissue water as measured by RWC. Photosynthesis is closely related to dry matter production in most crops, even though it has been argued that instantaneous measurements of photosynthesis is ambiguous and that crop yield is more linked to the net photosynthetic assimilation of $\mathrm{CO}_{2}$ over the whole season (Zelitch, 1982).

AHM-753 landrace maintained higher leaf water and had also higher photosynthesis after the water deficit treatment in comparison to Bogor and can thus be considered to have more drought tolerance potential than Bogor. This may not be surprising considering the fact that AHM-753 is an African landrace adapted to an environment with low annual mean precipitation (mean annual rainfall in Namibia is $370 \mathrm{~mm}$ (www.climateinfo.info/namibia)). On the other hand, Bogor an Indonesian landrace is adapted to a much wetter environment (mean annual rainfall $1755 \mathrm{~mm}$ (www.climateinfo.info/indonesia)).

Changes in the rates of gas exchange parameters are among the indicators of responses and adaptation to stress. Decrease in transpiration and stomatal conductance points to the possibility of a drought avoidance strategy in Bambara groundnut having the ability to maintain relatively high tissue water content under soil water deficit. The results of this work also pointed at the ability of Bambara groundnut to recover well from the effects of water deficit when conditions return to normal.This report has pointed some important physiological responses to water deficit in the seedlings of selected Bambara groundnut landraces.

\section{CONCLUSION}

Results of this study have shown a decrease in relative water content, photosynthetic and transpiration rates, stomatal conductance and SPAD chlorophyll in Bambara groundnut in response to imposed water deficit. Differences were observed in the response between the landrace AHM-753 and Bogor indicating that the source of a landrace, i.e. the environment it is adapted to, determines its response to water deficit. 


\section{REFERENCES}

Aphalo, P.J. and Jarvis, P.G. (1991). Do stomata respond to relative humidity? Plant, Cell and Environment 14(1), 127-132.

Arunyanark, A., Jogloy, S., Akkaseng, C., Vorasoot, N., Kesmala, T., Nageswara Rao, R.C., Wright, G.C. and Patanothai, A. (2008). Chlorophyll stability is an indicator of drought tolerance in peanut. Journal of Agronomy and Crop Science 194, 113125.

Song, L. and Assmann, S.M. (2010). Genetic determinants of stomatal function in: M.A. Jenks and A.J. Wood (Eds.) Genes for Plant Abiotic Stress, pp. 5-25. WileyBlackwell, Ames, IA.

Basu, S., Mayes, S., Davey, M., Roberts, J.A., AzamAli, S.N., Mithen, R. and Pasquet, R.S. (2007). Inheritance of domestication traits in bambara groundnut (Vignasubterranea (L.) Verdc.). Euphytica, 157(1), 59-68.

Berchie, J.N., Opoku, M., Adu-Dapaah, H., Agyemang, A., Sarkodie-Addo, J., Asare, E.,Addo, J. and Akuffo, H. (2012). Evaluation of five Bambara groundnut (Vigna subterranea (L.) Verdc.) landraces to heat and drought stress at TonoNavrongo, Upper East Region of Ghana. African Journal of Agricultural Research 7 (2), 250-256.

Campbell, R.J., Mobley, K.N., Marini, R.P. and Pfeiffer, D.G. (1990). Growing conditions alter the relationship between SPAD-501 values and apple leaf chlorophyll. HortScience 25(3), 330-331.

Chaves, M.M. and Oliveira, M.M. (2004). Mechanisms underlying plant resilience to water deficits: prospects for water-saving agriculture. Journal of Experimental Botany 55(407), 2365-84.

Chaves, M.M., Maroco, J.P. and Pereira, J.S. (2003). Understanding plant responses to drought: from genes to the whole plant. Functional Plant Biology 30, 239-264.

Collinson, S.T., Berchie, J. and Azam-Ali, S.N. (1999). The effect of soil moisture on light interception and the conversion coefficient for three landraces of Bambara groundnut (Vigna subterranea). Journal of Agricultural Science 133, 151157.

Cominelli, E., Galbiati, M., Tonelli, C. and Bowler, C. (2009). Water: the invisible problem. EMBO Reports10(7), 671-676.

Gindaba, J., Rozanov, A. and Negash, L. (2004). Response of seedlings of two Eucalyptus and three deciduous tree species from Ethiopia to severe water stress. Forest Ecology and Management 201(1), 119129.

Grantz, D.A. (1990). Plant response to atmospheric humidity. Plant, Cell and Environment.13(7), 667-679.
Grassi, G. and Magnani, F. (2005). Stomatal, mesophyll conductance and biochemical limitations to photosynthesis as affected by drought and leaf ontogeny in ash and oak trees. Plant, Cell and Environment 28(7), 834-849.

Hadley, J.L., Smith, W.K. (1990).Influence of leaf surface wax and leaf area to water content ratio on cuticular transpiration in western conifers, USA. Canadian Journal of Forest Research20(9), 1306-1311.

Hawkins, T.S., Gardiner, E.S. and Comer, G.S. (2009). Modelling the relationship between extractable chlorophyll and SPAD-502 readings for endangered plant species research. Journal for Nature Conservation 17, 123-127.

Jorgensen, S.T., Liu, F., Ouedrago, M., Ntundu, W.H., Sarrazin, J. and Christiansen, J.L. (2010). Drought responses of two Bambara groundnut (Vigna subterranea L. Verdc.) landraces collected from a dry and humid area of Africa. Journal of Agronomy and Crop Science 196, 412422.

Kimani, P.M., Benzioni, A. and Ventura, M. (1994). Genetic variation in pigeon pea (Cajanuscajan (L.) Mill sp.) in response to successive cycles of water stress. Plant and Soil 158(2), 193-201.

Li, F.L., Bao, W.K. and Wu, N. (2011). Morphological, anatomical and physiological responses of Campylotropis polyantha (Franch.) Schindl. seedlings to progressive water stress. ScientiaHorticulturae127(3), 436443.

Linnemann, A.R and Azam-Ali, S.N. (1993). Bambara groundnut (Vigna subterranea). In J.T. Williams (ed.), Underutilised Crops. Pulses and Vegetables,pp. 13-57. Chapman and Hall, London.

Loh, F., Grabosky, J. and Bassuk, N. (2000). Use of the Minolta SPAD-502 to determine chlorophyll concentration in Ficusbenjamina L. and Populusdeltoides marsh leaf tissue. HortScience 35(3), 423-424.

Mwale, S.S., Azam-Ali, S.N. and Massawe, F.J. (2007). Growth and development of Bambara groundnut (Vigna subterranea) in response to soil moisture 1 . Dry matter and yield. European Journal Agronomy 26, 345-353.

Nunes, C. and Araújo, S.S. (2008). Physiological responses of the legume model Medicagotruncatula cv. Jemalong to water deficit. Environmental and Experimental Biology 63, 289-296.

Rehman, S., Harris, P.J.C. and Ashraf, M. (2005). Stress environments and their impact on crop production. In M. Ashraf and P.J.C. Harris (eds.) Abiotic stresses: Plant Resistance through Breeding and 
Bajopas Volume 8 Number 1June, 2015

Molecular Approaches,pp. 3-18. Food

Sanchez-Blancoa, M.J., Ferra'Ndeza, T., Navarrob, A., Banon, S. and Alarco, J.J. (2004). Effects of irrigation and air humidity preconditioning on water relations, growth and survival of Rosmarinusofficinalis plants during and after transplanting. Journal of Plant Physiology 161, 1133-1142.

Sibley, J., Eakes, D., Eakes, D.J., Gilliam, C.H., Keever, G.J., Dozier, W.A. and Himelrick, D.G. (1996). Foliar SPAD-502 Meter Values, Nitrogen Levels, and Extractable Chlorophyll for Red Maple Selections. HortScience 31(3), 468-470.

Teulat, B.,Rekika, D., Nachit, M.M. and Monneveux, P. (1997). Comparative osmotic adjustments in barley and tetraploid wheats. Plant Breeding 116(6), 519-523.
Products Press, New York.

Tezara, W., Mitchell, V.J., Driscoll, S.D. and Lawlor, D.W. (1999). Water stress inhibits plant55 photosynthesis by decreasing coupling factor and ATP. Nature 1401, 914-917.

Urano, K., Kurihara, Y., Seki, M. and Shinozaki, K. (2010). 'Omics' analyses of regulatory networks in plant abiotic stress responses. Current Opinion in Plant Biology 13, 1-7.

Van Der Mescht, A., De Ronde, J.A. and Rossouw, F.T. (1999). Chlorophyll fluorescence and chlorophyll content as a measure of drought tolerance in potato. South African Journal of Science 95(9), 407412.

Wilson, J., Ludlow, M.M., Fisher, M.J. and Schulze, E. (1980). Adaptation to Water Stress of the Leaf Water Relations of Four Tropical Forage Species. Australian Journal of Plant Physiology 7(2), 207.

ZelitchI. (1982). The close relationship between net photosynthesis and crop yield. BioScience32, 796-802. 